\title{
Transfistula Anorectoplasty (TFARP): Better Surgical Technique for the Management of Vestibular Fistula
}

\author{
Khan $\mathrm{JG}^{1}$, Ali MA², Yusuf MA ${ }^{3}$, Islam $\mathrm{MK}^{4}$, Rahaman $\mathrm{MA}^{5}$, Hasina $\mathrm{K}^{6}$, Akter J ${ }^{7}$, Sharif $\mathrm{AR}^{8}$, Talukder Ak ${ }^{9}, \mathrm{Ahsan} \mathrm{AI}^{10}$
}

\begin{abstract}
Background: Many approach have been tried for management of vestibular fistula, most of them have post operative complication like wound infection, wound dehiscence, more hospital stay which compromise the functional out come and aesthetic appearance of the perineum. Objective: The aim of present study was to see the effectiveness of Transfistula Anorectplasty (TFARP) Which was required minimal dissection without interruption of perineal body and perineal skin. Methodology: The cross sectional study on 43 patients with vestibular fistula were held in Dhaka Shishu Hospital from September 2008 to April 2010. Patients were operated after obtaining informed consent and standard bowel preparation. Data on demographics, operation time and postoperative complications were collected as a questionnaire and plotted on Microsoft Excel and analyzed systematically by SPSS version 17. Patients were followed up for a period of $2 \frac{1}{2}$ months postoperatively. Results: There is no statistical deference in patient population regarding age, geographical distribution, and clinical presentation. Mean operation time was 76.5 min for TFARP and 84.34 min for ASARP. Two (02) cases had wound infection after TFARP operation and 11 patients after ASARP operation. One patient develops partial wound dehiscence after TFARP and was healed after conservative treatment within 7 days. On the other hand 05 patients developed partial wound dehiscence and 04 patients developed complete wound disruption after ASARP which were also treated conservatively need more than 2 weeks on an average. Mean hospital stay were 6.45 days after TFARP operation and mean hospital stay were 7.87 days after ASARP operation. 20 neonates and infant who were treated by TFARP operation have good bowel movement without laxative and symmetrical anal contraction after stimulation. Conclusion: TFARP is an operation produce less morbidity and is more effective procedures and superior procedures than that of ASARP operation and give aesthetic appearance of the perineum.Key words: Anorectal malformation, vestibular fistula, transfistula anorectoplasty
\end{abstract}

\section{Introduction}

Anorectal malformation represents a wide spectrum of defects approximately $1 / 5000$ with slight preponderance of male ${ }^{1}$. Recotvestibular fistula is the most common defect in female child ${ }^{2}$. Optimal surgical repair would be easy to assess minimum dissection to spare pelvic nerves and guide the rectal pouch through the muscles of continence and intact sphincter. In recto-vestibular fistula, rectum opens immediately behind the hymen in the vestibule. Okada et $\mathrm{al}^{3}$ devised ASARP, where perineal skin, perineal body was cut through the midline perineal incision. But
Akshay et $\mathrm{al}^{4}$ describe newer technique TFARP without cutting the perineal skin and perineal body. The purpose of present study was to see the effectiveness of Transfistula Anorectplasty (TFARP) Which was required minimal dissection without interruption of perineal body and perineal skin.

\section{Methodology}

This randomized control trial was planned to conduct at the Department of Paediatric Surgery of Dhaka Shishu Hospital from 2009 to 2010 for a period of 2 years. The patients who were presented with vestibular fistula from 1 to 12 months of age were included in this study. Patients

1. Dr. Jaglul Gaffer Khan, Medical Officer, SOPD, Dhaka Medical College Hospital, Dhaka

2. Dr. Md. Ansar Ali, Department of Pediatric Surgery, Dhaka Medical College Hospital, Dhaka

3. Dr. Md. Abdullah Yusuf, Lecturer, Department of Microbiology, Shaheed Suhrawardy Medical College, Dhaka

4. Prof. Mohammad Kabirul Islam, Department of Pediatric Surgery, Dhaka Shishu Hospital, Dhaka

5. Dr. M.A. Rahaman, Associate Professor, Department of Pediatric Surgery, Dhaka Shishu Hospital, Dhaka

6. Dr. Kaniz Hasina, Assistant Professor, Department of Pediatric Surgery, Dhaka Medical College Hospital, Dhaka

7. Dr. Jamila Akter, Lecturer, Department of Community Medicine, Uttara Adhunic Medical College, Dhaka

8. Dr. Ahmad Raihan Sharif, Medical Officer, Department of Virology, IEDCR, Dhaka

9. Dr. Abdur Rabban Talukder, Senior Consultant, Department of Surgery, General Hospital, Sirajgonj

10. Dr. Ali Imam Ahsan, Junior Consultant, Society for Assistance to Hearing Impaired Children (SAHIC), Dhaka

CorrespondenceDr. Md. Ansar Ali, MBBS, MS (Paediatric Surgery), Medical Officer, Civil Surgeon Office, Jessor, Bangladesh; Email: dr.ansar09@gmail.com, Mobile : +8801912770441 
with colostomy and/or severe systemic disease or history of surgery in the perineum were excluded. The patients were selected by purposive sampling and were divided in group A who were treated by ASARP and group B who were treated by TFARP surgical technique. The treatment option was given after randomization of the patients. The hospital ethical committee had approved the study before conducting the surgical procedure. Two different surgical techniques were comparing with the following variables like wound infection, wound dehiscence, and operation time. All the patients were prepared preoperatively with standard bowel preparation with erythromycin and metronidazole and rectal irrigation by normal saline and nothing per oral for 48 hours. Injection vitamin $\mathrm{K}$ was given to the neonate. Routine investigations like $\mathrm{Hb} \%, \mathrm{TC}$, DC, serum electrolytes, urea, creatinine, bleeding time (BT), clotting time (CT), blood grouping and cross matching, ultrasonography of KUB region and pelvic organ. Special investigations like Echocardiography, intravenous urography, X-ray spine were done. Before operative procedure proper counseling was done to obtain informed consent.

Surgical technique of TFARP: TFARP operation was performed under general anesthesia and patient was placed in lithotomic position. Site of the anus is marked by electro-stimulation. Circumfistula incision was given in the vestibule. Several fine silk traction sutures insertion around the fistula orifice.

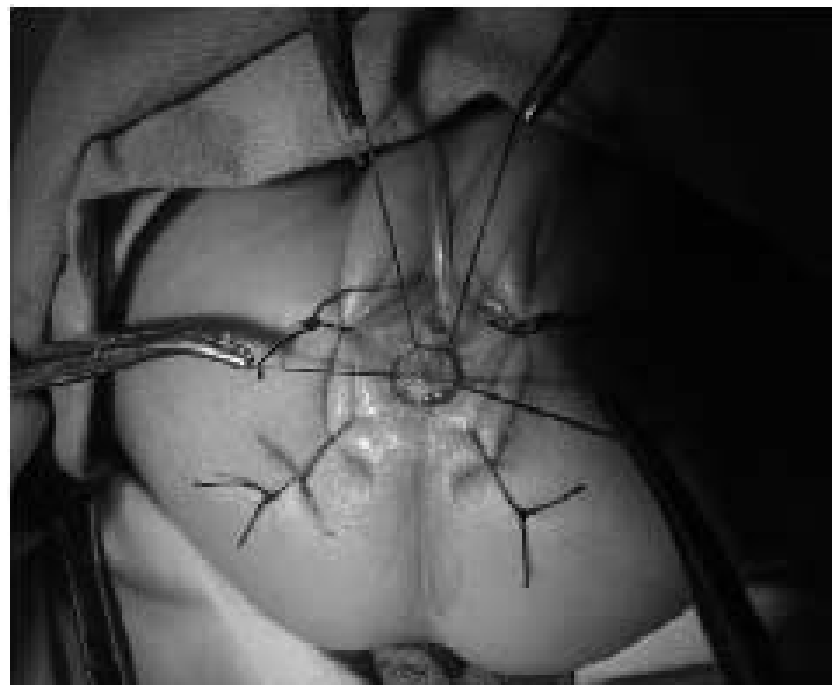

Fig 1: Circumfistula incision for TFARP

Separation of the rectum from the posterior vaginal wall was done by sharp dissection. Meticulous dissection of anorectum about 4 to $5 \mathrm{~cm}$ length was done with care not to damage the vagina or musculature enclosing the rectum. Homeostasis was ensured. Placement of mobilized rectum was performed at the proposed site of anus through centre of muscle complex with fixation of rectum to the muscle complex. Anoplasty was done by standard technique with apposition of vestibular wound.Surgical Technique of ASARP: In lithotomic position, site of the anus was marked by electrostimulation. Circumferential incision was given in the mucocutaneous junction at the opening of fistula with posterior extension along midline to reach the centre of external sphincter muscle (anal dimple).

Several fine silk traction sutures were given around the fistula orifice. Separation of rectum from posterior vaginal

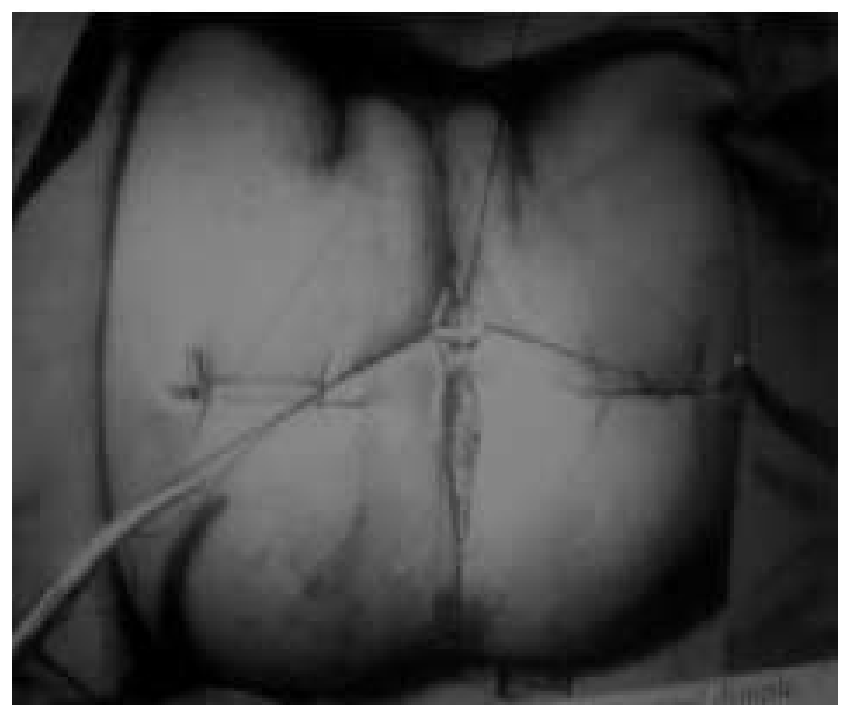

Fig 2: Racket incision for ASARP

wall was done by sharp dissection. Meticulous dissection of anorectum (around 4 to $5 \mathrm{~cm}$ length) was done with care being taken not to cause damage to the musculature enclosing the rectum.

Retro-rectal division of muscle complex was performed with sparing of pubo-rectalis muscle and electro

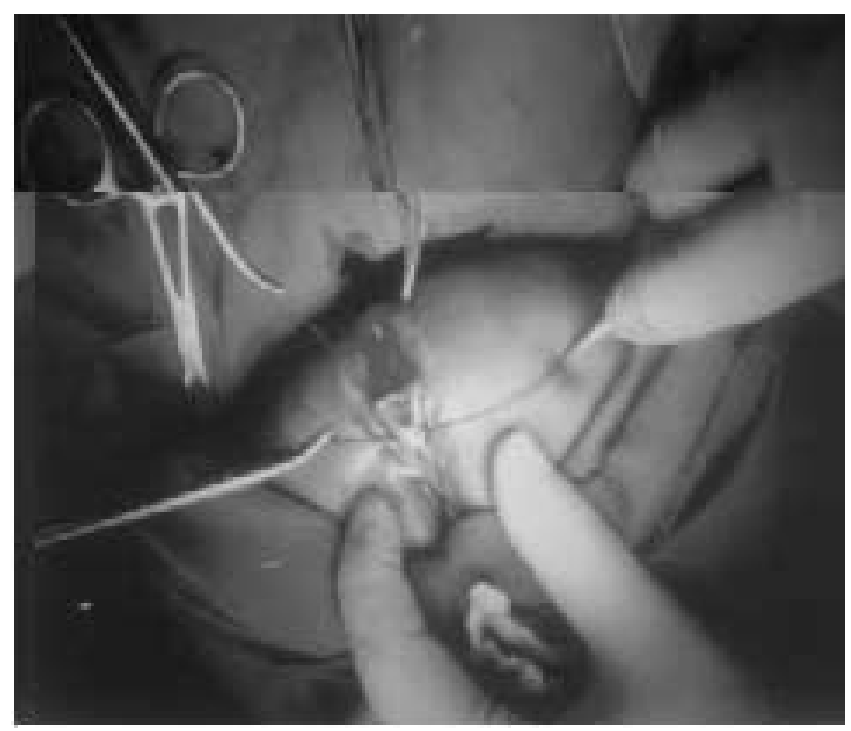

Fig 3: Mobilization of rectum through perineal wound

coagulation of bleeding vessels was done with the placement of mobilized rectum backward at the centre of muscle complex and apposition of anterior end of fan 
shaped muscles was done as well with suturing by interrupted stitches. Fixation of rectum to the muscle over its entire circumference by interrupted stitches and anoplasty was done.

Reconstruction of perineal body with apposition of vestibular and perineal wound was performed.

Post operative management: For post operative treatment paracetamol was given with a dose of $15 \mathrm{mg} / \mathrm{kg} / \mathrm{dose}$ for pain relief in neonate and infant. Foley's catheter was kept in situ for 5th POD and aqueous povidone iodine solution was applied to the wound and neoanus several times. Oral feeding was started on 1 st postoperative day (POD). Perentral antibiotic continued for 5th POD. Anal dilatation was started on 14th POD. Follow up were done on 14th day, 44th day and 74th day. ResultsA total number of 3712 patients were admitted during the study period of which $235(6.3 \%)$ were diagnosed as a case of anorectal malformations.

Among 235 anorectal malformations vestibular fistula was found in 43(18.3\%) cases of which RVF and AVF were in $30(69.8 \%)$ and $13(30.2 \%)$ cases respectively. These total

Table 1 : Age distribution of patients with vestibular fistula $(n=43)$

\begin{tabular}{lcc}
\hline $\begin{array}{l}\text { Age group } \\
\text { (Months) }\end{array}$ & Frequency & Percentage \\
\hline $0-1$ & 25 & 58.1 \\
$1-6$ & 11 & 25.6 \\
$6-12$ & 07 & 16.3 \\
Total & $\mathbf{4 3}$ & $\mathbf{1 0 0}$ \\
\hline
\end{tabular}

Mean age $\pm \mathrm{SD}=2.79 \pm 2.9$ (range 1-12)

43 patients were included in this study from 1 day to 12 months age to compare operative technique for the management of vestibular fistula.

Among them 20 patients were under went TFARP operation and 23 patients were operated by ASARP technique. The mean age with $\mathrm{SD}$ is $2.79 \pm 2.9$ months

Table 2 : Time required for each operation

\begin{tabular}{lcc}
\hline $\begin{array}{l}\text { Duration of } \\
\text { Operation }\end{array}$ & TFARP & ASARP \\
\hline Mean time (min) & 76.5 & 84.3 \\
Std deviation & 10.64 & 7.12 \\
\hline *Independent t test was dove & *P value 0.018 &
\end{tabular}

(Table I). The mean duration with SD of operation technique is $76.5 \pm 10.64$ and $84.3 \pm 7.12$ minutes in TFARP and ASARP respectively ( $\mathrm{p}=0.018$ ) (Table II). Vaginal wall injury is more common in ASARP than TFARP which are $7(30.4 \%)$ cases and $4(20.0 \%)$ cases respectively $(p=0.501)$. Wound infection is more common in ASARP than TFARP which are $11(47.8 \%)$ cases and $2(10.0 \%)$ cases respectively $(\mathrm{p}=0.009)$ (Table III).
Perineal wound is healed more in TFARP than ASARP which is $19(95.0 \%)$ and $14(60.9 \%)$ cases respectively

Table 3 : Vaginal wall injury and Wound infection during TFARP \& ASARP

\begin{tabular}{lccc}
\hline Technique & $\begin{array}{c}\text { Vaginal wall } \\
\text { injury }\end{array}$ & $\begin{array}{c}\text { Wound } \\
\text { infection }\end{array}$ & Total \\
\hline TFARP & $4(20.0)$ & $2(10.0)$ & $\mathbf{6}$ \\
ASARP & $7(30.4)$ & $11(47.8)$ & $\mathbf{1 8}$ \\
*P value & 0.501 & 0.009 & \\
\hline
\end{tabular}

*Pearson Chi-square test has been done $\&$ corrected by Fishers exact test

$(p=0.025)$ (Table IV). The mean postoperative hospital stays after TFARP and ASARP operation are $6.95 \pm 1.572$ and $7.87 \pm 2.302$ days respectively (table $\mathrm{V}$ ).

DiscussionIn 20 months of study a total of $235(6.3 \%)$ patients of anorectal malformations were admitted in Dhaka Shishu Hospital, among them 43 (18.29\%) female patients with vestibular fistula were included in the study. Though this was a single institution based study, this result showed some light in this respect in Bangladesh. In previous study in this hospital, the total hospital admission of ARM was $214,7.8 \%$. In this study rectovestibular fistula $30(69.77 \%)$ was larger in number than anovestibular fistula, $30.23 \%$. This observation is similar to Pena ${ }^{5}$.

In this study age distribution ranged from 1 day to 12 months, among them 25 (58.1\%) were $0-1$ month,

Table 4 : Perineal wound after ASARP and TFARP operation

\begin{tabular}{lcccc}
\hline \multirow{2}{*}{ Perineal wound } & \multicolumn{2}{c}{ TFARP } & \multicolumn{2}{c}{ ASARP } \\
\cline { 2 - 5 } & Count & $\mathbf{\%}$ & Count & $\mathbf{\%}$ \\
\hline Healed & 19 & 95.0 & 14 & 60.9 \\
Partial Disruption & 1 & 5.0 & 5 & 21.7 \\
Complete Disruption & 0 & 0 & 4 & 17.4 \\
Total & $\mathbf{2 0}$ & $\mathbf{1 0 0}$ & $\mathbf{2 3}$ & $\mathbf{1 0 0}$ \\
\hline
\end{tabular}

*ANOVA has been done and the difference between the two operative technique is significant $(\mathrm{P}=0.025)$

$11(25.6 \%)$ patient were 1 to 6 months and $07(16.3 \%)$ patients were 6 months to 12 months. So maximum number of patients were between $0-1$ months, which shows early

presentation due to absence of anus and passages of meconium through abnormal opening. This early presentation may be due to increase number of health care personale at District, Upazila and Union health sub centre. It is similar to other study findings by Okada et $\mathrm{al}^{6}$.

The operative procedures performed in this study were 
both TFARP (20) and ASARP (23) with the guidelines as mentioned by Akshay et $\mathrm{al}^{4}$ for TFARP, Okada et $\mathrm{al}^{6}$ for ASARP. In TFARP operation, $4(20 \%)$ patients out of 20 patient had vaginal wall injury and 7 (30.4\%) had vaginal wall injury among 23 patient during ASARP operation. In Akshay et $\mathrm{al}^{4}$ one patient developed a vaginal tear, in this study incidence of vaginal tear was more there. Those vaginal tear were repaired during operation, none of them developed further complication like fistula.

Table 5 : Postoperative hospital stays after ASARP and TFARP operation

\begin{tabular}{lcc}
\hline $\begin{array}{l}\text { Duration of } \\
\text { Hospital stay }\end{array}$ & TFARP & ASARP \\
\hline Mean (Days) & 6.95 & 7.87 \\
Std deviation & 1.572 & 2.302 \\
\hline
\end{tabular}

Minimum time required for a TFARP operation was 65 minutes and maximum time required 95 minutes, in ASARP operation minimum time was 70 minutes and maximum time 95 minutes. Mean time 76.5 minutes $\mathrm{SD} \pm 10.64$ minute for TFARP and mean time 84.3 minutes with SD \pm 7.11 minute for ASARP which is statistically significant $(\mathrm{p}=0.018)$, The mean operation time in Akshay et $\mathrm{al}^{4}$ was 85 minute. Decreased operation time is encouraging.

Majority of patient were discharged on 6th post operative day (POD) and mean hospital stay was 6.95 days with a $\mathrm{SD}$ of 1.57 days for TFARP and mean \pm SD is $7.9 \pm 2.3$ days. Akshay et $\mathrm{al}^{4}$ was found 5 days mean hospital stay. At the time of discharge all parents were requested to report for planned schedule of follow up and anal dilatation. All the patients were examined on 2 nd and 5 th POD to see the wound whether infection was present or not, it was found that $2(10 \%)$ patients had wound infection in TFARP operation. On the other hand 11(47.8\%) ASARP operation had wound infection. If any sign of infection appears it was added third antibiotic (Flucloxacine). On 5th POD again the wound was examined and found that those patients who had undergone TFARP operation healed $19(95 \%)$, and $1(5 \%)$ had partial wound disruption. On the other hand ASARP, 14(60.9\%) patients healed completely but $5(21.7 \%)$ had partial wound disruption and $4(17.4 \%)$ patients had complete wound disruption. In Akshay et $\mathrm{al}^{4}$ series all 25(100\%) patients vestibular wound healed completely; in this study TFARP series $1(5 \%)$ case had vestibular wound disruption which healed spontaneously with conservative treatment.

In patients who had wound dehiscence were kept for more days and started Hip bath, none of them required further operative procedure. All the parents were advised to come back on 14th POD, for 1st follow up; there after 1 month for 2nd follow up \& 3rd follow up 1 month after 2nd follow up. In each visit condition of the wound, neoanal site, size, appearance of the perineum, enquired about frequency and constipation.
Then anal dilatation carried out with appropriate size Hegar dilator after lubrication with $2 \%$ lignocaine jelly, dilatation procedure were demonstrated to the parents for future dilatation at home, with local made metallic anal dilator calibrated with proper size Hegar dilator, by researcher according to Pena's anal dilatation schedule. In this study all the patients came for follow up, as per our schedule. At the end of follow up, the result and short term outcome of TFARP and ASARP were evaluated. Functional outcome with regard to wound infection, wound dehiscence, cosmetic appearance were noted. Look of the perineum was normal in all (20) patients who had TFARP operation except $1(5 \%)$ who had vestibular wound partial disruption and those who had ASARP 9(39.1\%), had displeasing appearance of the perineum who developed wound infection and dehiscence. Consistency of the fecal matter was normal and none of them required laxative postoperatively. Most of the patients' postoperative period was uneventful.

The study had some limitation. It was carried out on a small number of 20 cases of TFARP, 23 cases of ASARP in a short period of 20 months, the follow up period was also short to give a final verdict about the outcome.

So short term outcome without any complication in TFARP 19 out of 20 patients and ASARP 14 out of 23 patients was considerable. Thus, TFARP approach is more acceptable than ASARP with regard to surgical outcome and aesthetic appearance of perineum as there is no visible scar mark in the perineum, and strength of perineum in contrast to weak perineum and visible scar mark in ASARP. Though sample size was small, follow up period of study was short and patients are still under anal dilatation.

\section{Conclusion}

Transfistula Anorectoplasty (TFARP) is more effective, preferable and superior procedure to that of Anterior Sagittal Anorectoplasty (ASARP) to reduce the postoperative morbidity and aesthetic appearance of the perineum for the surgical treatment of vestibular fistula. However more studies need to be done on Transfistula Anorectoplasty (TFARP) to prove its effectiveness and superiority to establish it as a standard technique for the future.

\section{Acknowledgement}

I would like to sincerely thank to Prof. Dr. A. R. Khan, Prof. A. Aziz, and all my colleagues others medical stuff of Dhaka Shishu Hospital, who has helped me during this study period. 


\section{References}

1. Pena A. 'Imperforate anus and cloacal malformations' in pediatric surgery, 3rd edn, ed. KW, Ashcraft, W.B. Saunders company, Philadelphia, 2000, pp.473-492

2. Wakhlu A, Pandey A, Prasad A, Kureel SN, Tandon RK, Wakhlu AK. 'Anterior sagittalanorectoplasty for anorectal malformations and Perineal trauma in the female child', J. Pediatr Surg. 1996; 31(9):1236-1240

3. Okada A, Shinkichi, K, Imura, K, Fukuzawa, M, Kubota, A, Yagi, M, Azuma,T, Tsuji, H 'Anterior saittal anorectoplasty for Recovestibular and anovestibular fistula, J. Pediatr surg, 1992; 27 (1): 85-88

4. Akshay P, Yadav RP, Shekhar VC, Singh A, Sen R. One stage correction of Rectovestibular fistula by transfistula anorectoplasty. J,World surg vol. 2007; 31( 9):1-3

5. Pena A. Anorectal anomalies'in Newborn surgery,2nd edn, ed.p. Puri, Arnold, London, 2003; 535-552

6. Okada A, Shinkichi K, Imura K, Fukuzawa M, Kubota A, Yagi M, Azuma T, Tsuji,H. Anterior Saittal Anorectoplasty for Rectovestibular and Anovestibular fistula, J Pediatr Surg, 1992:27(1):85-88

7. Ehsan MT. Single stage posterior sagittal anorectoplasty for high and intermediate variety of anorectal malformations in neonate. [M.S Thesis], Dhaka University, Dhaka. 2003 